\title{
HIGH-RESOLUTION, HIGH-FOLD SEISMIC REFLECTION PROFILE ACROSS A LANDFILL
}

\author{
R. De Iaco, H. Horstmeyer and A. Green \\ Institute of Geophysics, ETH-Hoenggerberg, Zurich, CH-8093, Switzerland
}

\begin{abstract}
SUMMARY
Fast and inexpensive methods for examining waste disposal sites are becoming increasingly important. We have tested reflection seismic techniques for mapping the depth extent of a landfill. Short geophone spacings and shot spacings together with a Bison 240-channel recording system provided high resolution and high subsurface coverage. Processed shot gathers reveal reflection hyperbolae with RMS velocities of $-250--400 \mathrm{~m} / \mathrm{s}$ and a prominent traveltime delay and offset of the first breaks. Reflections from the top $(-20 \mathrm{~ms})$ and bottom $(35-65 \mathrm{~ms})$ of the waste disposal site are prominent features of the shot gathers and stacked section. A combined interpretation of the stacked section and refracted events yields a model that is consistent with adjacent borehole data.
\end{abstract}

\section{INTRODUCTION}

A variety of geophysical techniques have been employed in a multi-disciplinary investigation of a landfill site in northwestern Switzerland (De Iaco et al., 1997). Objectives of our research have been to determine the lateral and depth extent of the landfill and to map possible contaminant plumes emanating from the waste. Seismic reflection, seismic refraction, ground-penetrating radar, magnetic, electromagnetic and resistivity data have been recorded across the site. Here, we present preliminary results of one of the seismic reflection surveys.

During the Riss ice age, 120,000 years ago, the area of interest was covered by a glacier. A number of boreholes indicate that the natural land is now characterized by a $1-2 \mathrm{~m}$ thick surface layer of humus and silty gravel overlying $10-15 \mathrm{~m}$ of silty and sandy gravel. Beneath the gravel are $5-10 \mathrm{~m}$ of lacustrine sediments composed of sandy clay and silt. The bedrock lies at a depth of about $20 \mathrm{~m}$. After excavation of the gravel to a depth of $-10 \mathrm{~m}$, the resulting pits were filled with household and construction waste. The landfill was then covered by $-2 \mathrm{~m}$ of sandy clay and $\sim 0.5 \mathrm{~m}$ of humus.

\section{DATA ACQUISITION}

One of the seismic reflection profiles was recorded across the landfill. Prelimminary tests demonstrated that because of unfavourable conditions encountered at this landfill, special care would be required during data acquisition. For example:

a) geophone spacings and shot spacings of $25 \mathrm{~cm}$ and the use of a Bison 240-channel recording system provided sufficient sampling of the important features and high subsurface coverage - our target depth of 0 $25 \mathrm{~m}$ was covered by source-receiver offsets of $0-54 \mathrm{~m}$;

b) vertical stacking of shotgun records provided data with good signal-to-noise ratios - the multiple shotgun source produced superior seismic records to those obtained with small dynamite charges;

c) good geophone coupling and a consolidated surface layer were critical for recording an interpretable data set.

Figure 1 shows the region of interest. It indicates the assumed extent of the waste disposal site (dotted area). The straight line marked CMP delineates the common midpoints covered by the survey.

\section{PROCESSING}

Editing of the shot gathers and filter tests demonstrated that data recorded from the second to fourth shots at most locations were noticably superior to those recorded from the first shot; depths of holes generally increased after each shot from an initial $50-60 \mathrm{~cm}$ just below the humus material to values of $80-90 \mathrm{~cm}$ after the final shot. Initial processing of the data included vertical stacking after correction for time shifts caused by the different shot depths and spectral balancing to suppress the surface waves. The prominent airwave energy (A in Fig. 2) was effectively cancelled by the high-fold stacking process. Application of a carefully designed multi-channel filter (F-X-deconvolution) considerably improved the continuity of the important features in the shot records and stacked section. The top mute (outlined by large dots in Fig. 2) applied before gaining the data with a short-window ( $30 \mathrm{~ms}$ ) AGC eliminated most of the refracted energy. On many shot gathers, reflections from as shallow as $20 \mathrm{~ms}$ may be distinguished by their distinctive hyperbolic shapes (see marked reflections $\mathrm{R} 1$ and R2 on Figs. 2a and 2b). Velocity analysis after CDP sorting revealed very low RMS velocities: $-250 \mathrm{~m} / \mathrm{s}$ at $-20 \mathrm{~ms}$ and 
$-400 \mathrm{~m} / \mathrm{s}$ at $35.65 \mathrm{~ms}$. Normal moveout corrections with a constant RMS velocity of $400 \mathrm{~m} / \mathrm{s}$ and subsequent stacking produced the best image.

\section{RESULTS}

Analyses of first breaks yielded velocities for the $-0.5 \mathrm{~m}$ thick humus layer of $-200 \mathrm{~m} / \mathrm{s}$ and velocities inside the sandy clay layer ranging from $-600 \mathrm{~m} / \mathrm{s}$ in the northwestem part of the profile to $-450 \mathrm{~m} / \mathrm{s}$ in the southeastem part. The distinctive traveltime delay and offset ( $R e$ in Fig. 2) are diagnostic of a low velocity layer (Banerjee and Gupta, 1975) underlying the sandy clay layer.

Reflection hyperbolae at $-20 \mathrm{~ms}$ ( $R 1$ in Fig. 2a) on shot gathers recorded along the northwestem part of the profile (distances 3-15 m in Fig. 3) allowed us to determine RMS velocities of $-250 \mathrm{~m} / \mathrm{s}$ for the two uppermost layers (i.e. to the base of sandy clay layer). Short sections of reflection hyperbolae (e.g. R2 in Fig. 2) with RMS velocities of $-400 \mathrm{~m} / \mathrm{s}$ can be seen on the inside -130 traces of most shot gathers at times $>35 \mathrm{~ms}$ (Note that only every second trace is plotted in Figs. 2 and 3). These reflections are interpreted to originate from the base of the landfill. Using Dix's formula, the calculated interval velocities within the waste material are $-380 \mathrm{~m} / \mathrm{s}$. The depth of the base of the landfill varies from $-12 \mathrm{~m}$ in the northwestem part of the profile to $-7 \mathrm{~m}$ in the southeastem part (undulating reflection $\mathrm{R} 2 \mathrm{in}$ Fig. 3 ), which is in accord with information from a nearby borehole. Since the top of the bedrock at about $20 \mathrm{~m}$ is not observed, most of the energy must have been either absorbed within the landfill or reflected at the interface between the landfill and the lacustrine sediments.

\section{CONCLUSIONS}

Interpretations of reflected and refracted energy yield a model that is consistent with borehole data. Reflection surveys are capable of mapping the top and the base of a waste disposal site if acquisition is carefully planned and implemented. Dense sampling of the subsurface using short geophone and shot spacings, high fold for improved signal-to-noise ratio, and sufficient shot depths are critical elements.

\section{REFERENCES}

Banerjee, B., and Gupta, S. K., 1975, Hidden Layer Problem in Seismic Refraction Work, Geophysical Prospecting, 23, $642-652$.

R. De Iaco, H. Horstmeyer, F. Lehmann, and A. Green, 1997, Georadar and electromagnetic studies of a landfill, submitted to SEG $67^{\text {th }}$ Annual Meeting in Dallas, Texas.

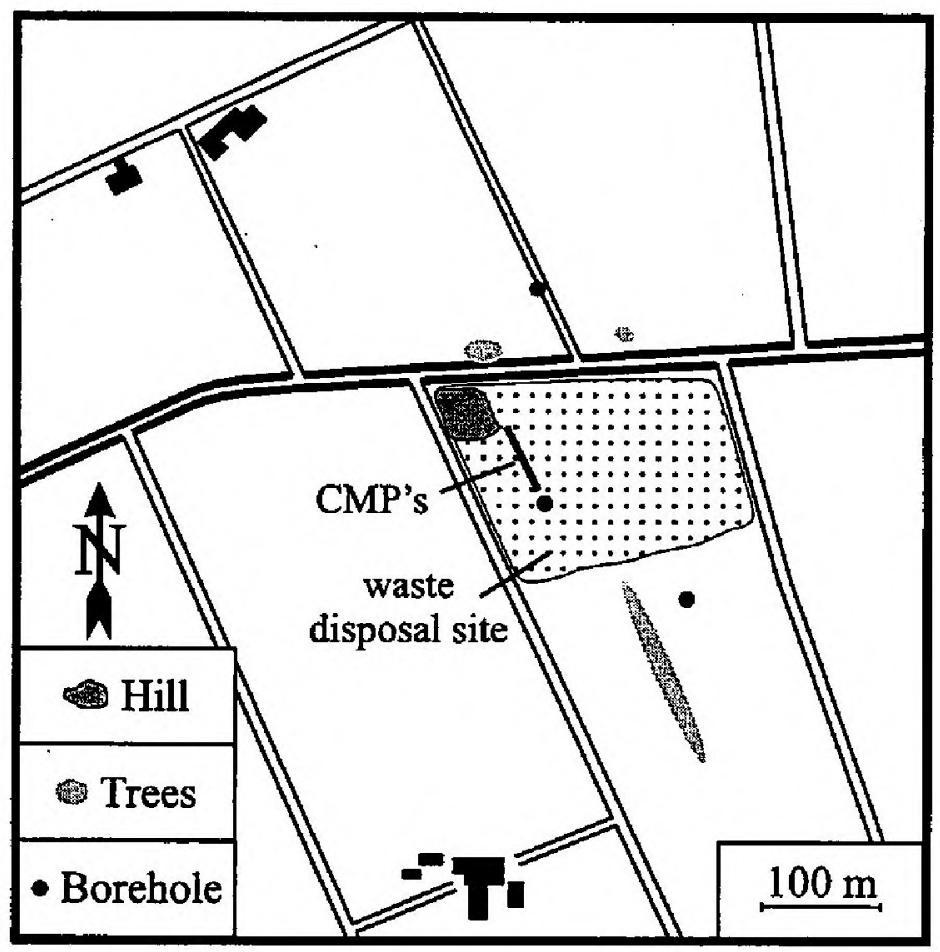

Figure 1

Location map of the investigation area. Dotted area outlines the assumed extent of the waste disposal site. Straight line indicates the common midpoints (CMP's) covered by the profile; the corresponding seismic section is shown in Fig. 3. 


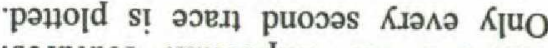

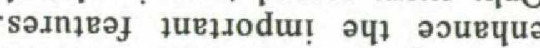

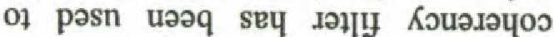
$\forall$ 'DDV (su 00I) морu!m-8ิuo e

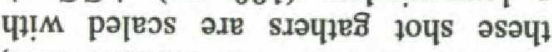

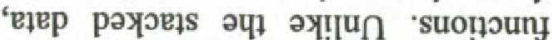

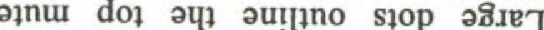

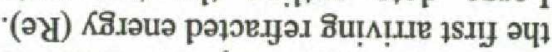

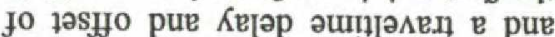

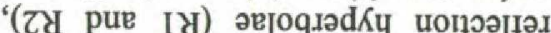

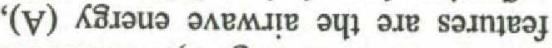

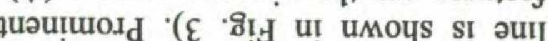

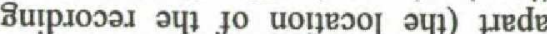

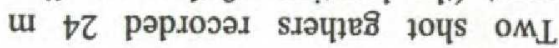
Z ว.กรเ!

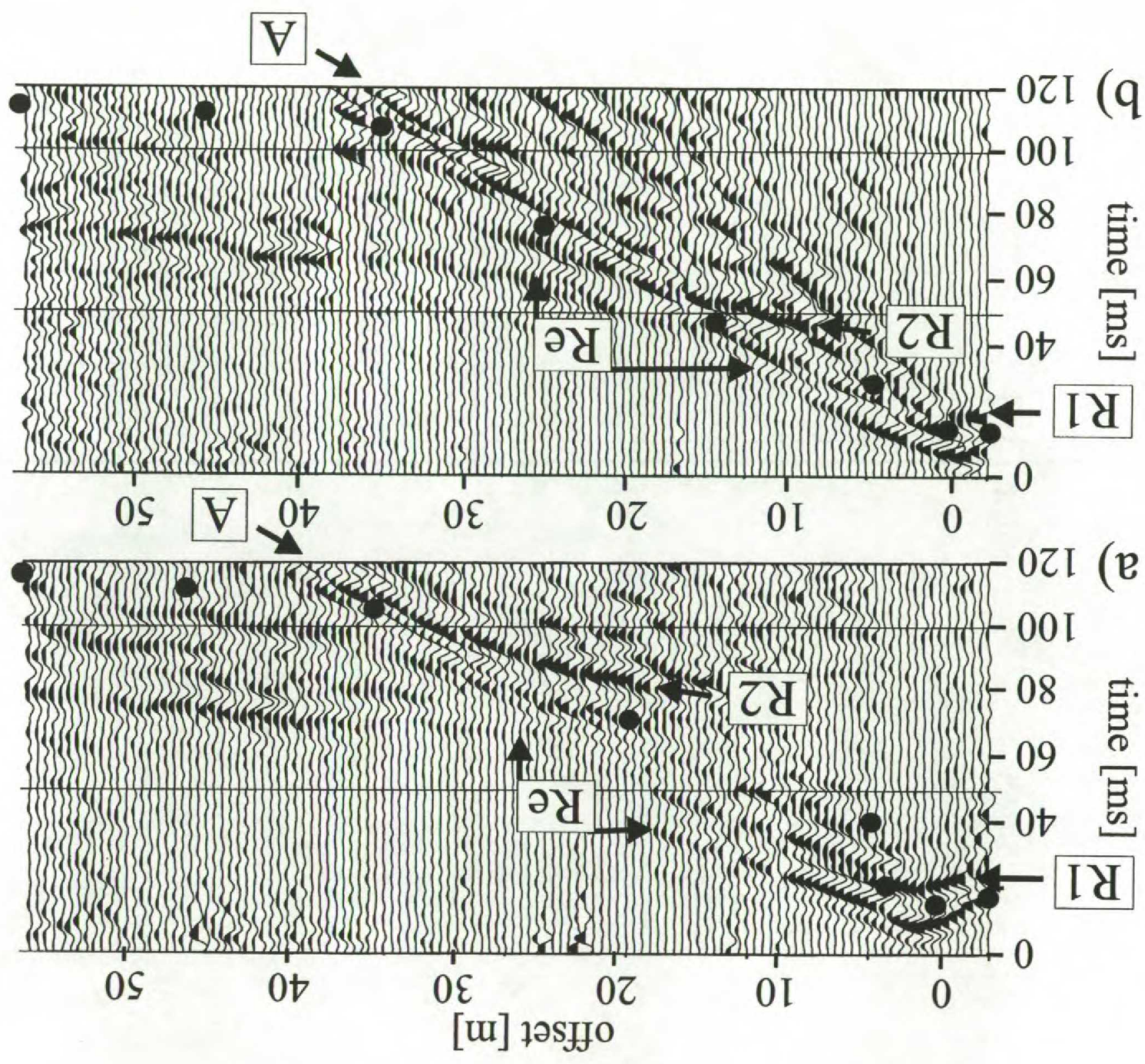




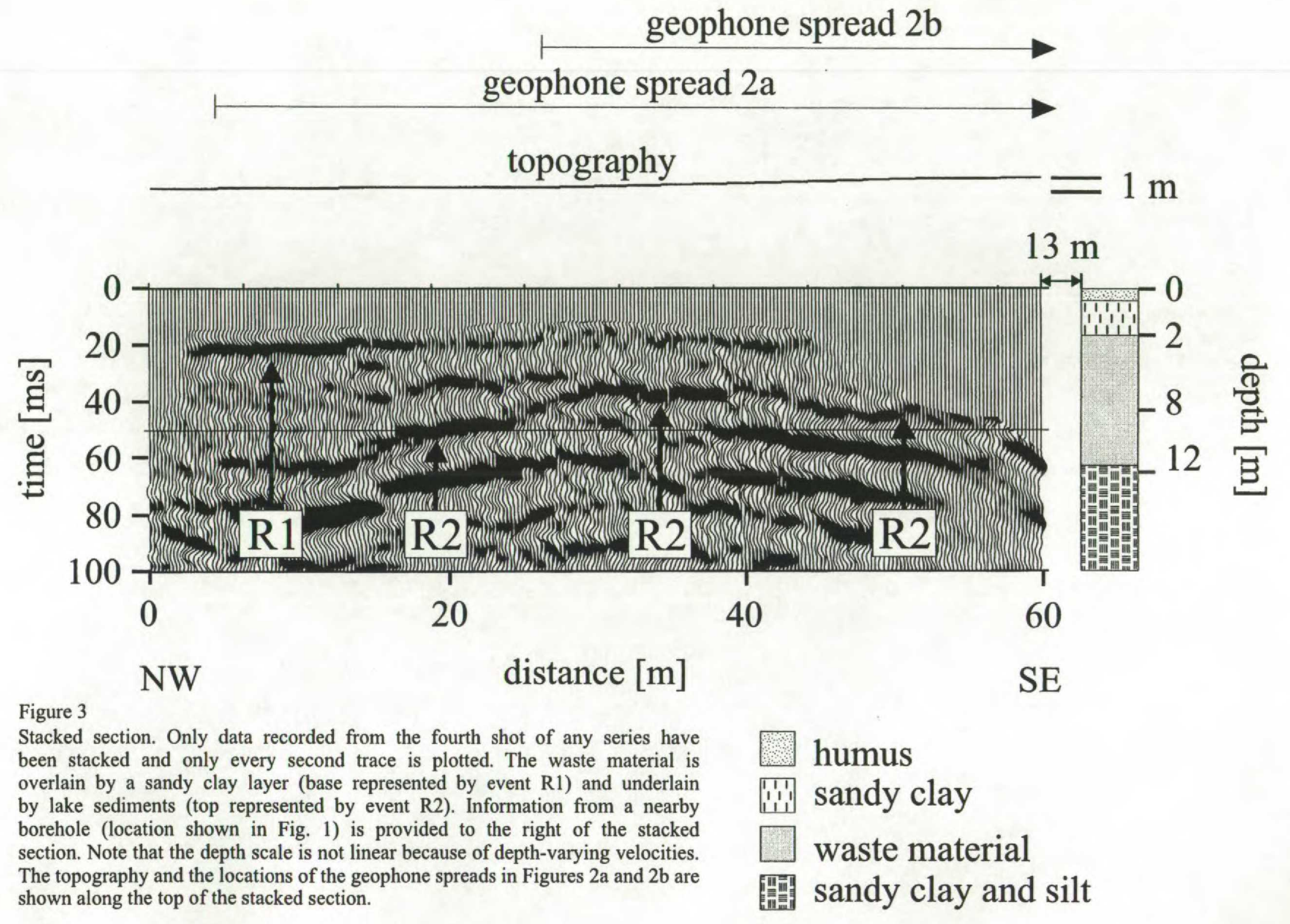

